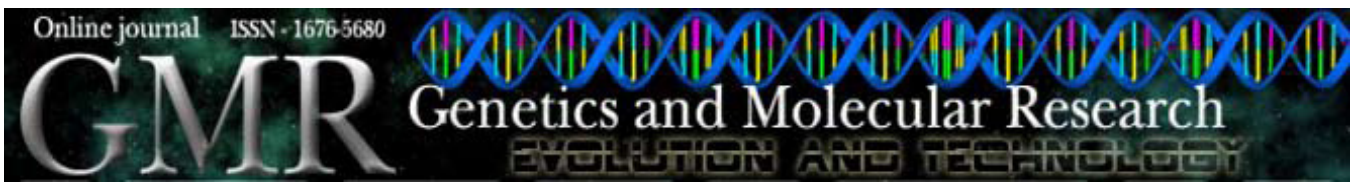

\title{
Inflammatory response to isocyanates and onset of genomic instability in cultured human lung fibroblasts
}

\author{
P.K. Mishra ${ }^{1}$, A. Bhargava ${ }^{1}$, G.V. Raghuram ${ }^{1}$, S. Gupta ${ }^{1}$, S. Tiwari ${ }^{1}$, \\ R. Upadhyaya ${ }^{2}$, S.K. Jain ${ }^{3}$ and K.K. Maudar ${ }^{1}$ \\ ${ }^{1}$ Department of Research, Bhopal Memorial Hospital \& Research Centre, \\ Bhopal, India \\ ${ }^{2}$ Madhya Pradesh Biotechnology Council, Bhopal, India \\ ${ }^{3}$ Department of Biotechnology, Dr. H.S. Gour University, Sagar, India \\ Corresponding author: P.K. Mishra \\ E-mail: pkm_8bh@yahoo.co.uk
}

Genet. Mol. Res. 8 (1): 129-143 (2009)

Received October 28, 2008

Accepted December 4, 2008

Published February 10, 2009

\begin{abstract}
Lungs comprise the primary organ exposed to environmental toxic chemicals, resulting in diverse respiratory ailments and other disorders, including carcinogenesis. Carcinogenesis is a multi-stage phenomenon, which involves a series of genetic alterations that begin with genomic instability provoked by certain factors such as inflammation and DNA damage and end with the development of cancer. Isocyanates such as methyl isocyanate are the chief metabolic intermediates in many industrial settings with diverse applications; exposure to them can lead to severe hypersensitive, mutagenic and genotoxic alterations. We examined the molecular mechanisms underlying isocyanate-mediated inflammatory responses and their probable role in the onset of genomic instability in cultured IMR-90 human lung fibroblasts. The isocyanates induced inflammation, resulting in extensive DNA damage, evidenced by increases in ATM, ATR, $\gamma \mathrm{H} 2 \mathrm{AX}$, and p53 expression levels. The apoptotic index also increased. Chromosomal anomalies in treated cells included over-expression of centrosome protein and variable amplification of inter-simple sequence repeats, further demonstrating isocyanate-induced genomic insta-
\end{abstract}


bility. This information could be useful in the design of new approaches for risk assessment of potential industrial disasters.

Key words: Inflammation; Genomic instability; DNA damage; Apoptosis; Isocyanates; Lung cancer

\section{INTRODUCTION}

Lungs comprise one the first organs of contact for most environmental exposures (excluding ingestion). Inflammation provides a potential mechanistic link between inhalation of toxic chemicals and the diverse health effects. Inflammatory stimulation in lungs accounts for exacerbations that significantly affect cellular respiration and lead to several chronic respiratory diseases as those in asthmatics and in patients with chronic obstructive lung disease.

Chemical inhalation injuries are serious and life-threatening problems. Isocyanates are the highly reactive ubiquitous compounds known to exert adverse health effects upon occupational or accidental exposure (Baur, 2003). They are often considered as potent respiratory allergens and are adept in causing a wide range of respiratory tract diseases including respiratory symptoms, inflammation, lung function impairment, and asthma (Lee et al., 2005; Redlich and Herrick, 2008). In addition, one of the major health concerns with isocyanate exposure is the risk of developing lung carcinogenesis; however, the genetic and molecular characteristics involved remain unclear (Mikoczy et al., 2004). As many cancers arise from the sites of inflammation, the concept that persistent inflammation has a versatile role in the onset of cancer has been documented recently (Mantovani et al., 2008). It is now becoming clear that the tumor microenvironment, which is largely orchestrated by inflammatory cells, is an indispensable participant in the neoplastic process, fostering proliferation, survival and migration (Coussens and Werb, 2002). Although, the precise function of inflammation in cancer progression remains to be elucidated, it is postulated that the release of inflammatory cytokines along with other factors into the tissue milieu causes oxidative damage, DNA mutations, and other changes in the microenvironment, potentially inducing genomic instability (Kundu and Surh, 2008).

Genomic instability is the most common molecular abnormality in mammalian cells that accelerates the process of carcinogenesis (Liloglou et al., 2001). Genomic instability initiates an increased rate of alterations, arising either from an excessive amount of damage overwhelming the ability of normal repair systems to restore genomic integrity, or defective repair systems being unable to cope with normal rates of damage generated through normal cellular and environmental mechanisms (Zhou and Elledge, 2000). Two members of the phosphatidylinositol-3 kinase-related kinase family, ATM (ataxia telangiectasia mutated) and ATR (ataxia telangiectasia and Rad3 related), are known to play a central role in DNA damage recognition and initial repair events (Abraham, 2004). Both ATM and ATR kinases, are activated in response to DNA-strand breaks leading to recruitment and phosphorylation of downstream proteins involved in the DNA damage response including H2AX (Ser139), and p53 (Ser15), further initiating cell signaling events to induce cell cycle arrest or apoptosis (Tibbetts et al., 1999; Kang et al., 2005).

In order to prevent the damaged DNA template to be processed during replication, the progression of cell cycle is arrested to avoid any additional damage, further allowing the cell to repair or prevent the transmission of damaged or incompletely replicated chromosomes and in addition to determine if cellular or DNA damage is compatible with cell survival or 
required cell elimination by apoptosis (Shiloh and Lehmann, 2004). This complete process is under tight regulation, and any imbalance in these processes may lead to hypersensitivity to cellular stress and susceptibility to DNA damage, genomic effects and resistance to apoptosis, thus initiating the cascade of carcinogenesis (Ishikawa et al., 2006). Down regulation of components of the DNA damage response mechanisms could enhance genomic instability and facilitate the proliferation of pre-cancerous cells (Gorgoulis et al., 2005). Isocyanates have the capability to spontaneously bind to biological macromolecules producing carbamoylated products. These products involve DNA cross links/adducts, which in turn contribute to cytotoxicity and detrimental effects (Beyerbach et al., 2006). In our previous findings, we have demonstrated that methyl isocyanate (MIC) is capable of undergoing bio-transformation reactions, i.e., DNA damage, apoptosis, oxidative stress, and inflammation in cultured human lymphocytes (Mishra et al., 2008). The paradigm that molecular mechanisms leading towards isocyanate-induced instability of the genome has received little or no attention.

The aim of our study was to ascertain the molecular mechanisms underlying the isocyanate-mediated inflammatory response and their probable role in the onset of genomic instability in cultured mammalian cells. The investigations were performed in the cultured human lung fibroblast IMR-90 cell line using N-succinimidyl N-methylcarbamate, a surrogate chemical to MIC (Martinez et al., 1982). Assessment of DNA damage kinetics was done through qualitative and quantitative evaluation of the extent of ATM, ATR, $\gamma \mathrm{H} 2 \mathrm{AX}$, and p53 phosphorylation states. Evaluation of apoptosis through annexin-V assay was carried out to determine the apoptotic index. The status of inflammatory cytokines secreted in culture supernatant prior to and following exposure was also done. Cytogenetic studies were performed in treated cells along with controls to check for the structural abnormalities induced in the genome, at chromosomal level and in addition, by inter-simple sequence repeat (ISSR)-polymerase chain reaction (PCR) to provide the prospects for ascertaining the further possible precariousness at the microsatellite level of the genome.

\section{MATERIAL AND METHODS}

\section{Reagents}

N-succinimidyl N-methylcarbamate [CAS No. 18342-66-0] (Sigma Aldrich Laboratories, St. Louis, USA) dissolved in $2 \mathrm{mM}$ DMSO with final concentration of $0.005 \mu \mathrm{M}(1 \mu \mathrm{g} /$ $\mu \mathrm{L}$ ) was used for investigations. Culture petri dishes were obtained from Nalgene-Nunc Inc., Roskilde, Denmark; antibiotic-antimycotic solution from Hi-Media Labs Pvt. Ltd., Mumbai, India; fetal bovine and calf serum from HyClone Labs, Logan, Utah, USA, and Eagle's minimal essential medium (EMEM) growth medium from Gibco/BRL Life Technologies, Inc., NY, USA. The cell growth supplements sodium pyruvate, nonessential amino acids and sodium bicarbonate were obtained from MP Biomedicals, Solon, USA. For studying DNA damage response kinetics, ATR, ATM, $\gamma \mathrm{H} 2 \mathrm{AX}$, and $\mathrm{p} 53$ and centrosomal protein pericentrin antibodies (Abcam, Cambridge, UK and Calbiochem, Nottingham, UK) were used with appropriate dilution in 1X PBS. To quantify apoptosis, the Annexin-V-fluorescein isothiocyanate (FITC)/ propidium iodide (PI) assay kit from Roche Applied Sciences, Mannheim, Germany, was used. Analysis of secreted levels of inflammatory cytokines was performed using the $\mathrm{BD}^{\mathrm{TM}}$ Multiplex Cytometric Bead Array (CBA) Human Inflammation kit from $\mathrm{BD}^{\mathrm{TM}}$ Biosciences, San Diego, USA. DNA cell cycle and ploidy analysis were performed using the $\mathrm{BD}^{\mathrm{TM}}$ Cycle 
TEST PLUS DNA Reagent kit, BD Biosciences, San Jose, USA. For assessment of microsatellite instability, the Wizard ${ }^{\circledR}$ Genomic DNA Purification kit and the PCR II Core System kit for PCR amplification (Promega Corporation, Madison, USA) were used.

\section{Cell lines and culture conditions}

IMR-90 human lung fibroblasts were obtained from the American Type Culture Collection (ATCC; Manassas, VA, USA). Cells were seeded at a density of $2 \times 10^{5}$ cells/60mm culture dishes in EMEM supplemented with $10 \%$ fetal bovine serum, $1.0 \mathrm{mM}$ sodium pyruvate, $0.1 \mathrm{mM}$ nonessential amino acids, $1.5 \mathrm{~g} / \mathrm{L}$ sodium bicarbonate at $37^{\circ} \mathrm{C}$ in the humidified atmosphere of $5 \% \mathrm{CO}_{2}$ in air according to ATCC catalogue instructions. After optimum confluency, the cells were exposed to the experimental agent, N-succinimidyl $\mathrm{N}$-methylcarbamate. At the onset of the experiments, the cells were at an exponential and asynchronous phase of growth.

\section{Study design}

The study comprised two major sections: a) analysis of inflammatory cytokine response, DNA damage and apoptotic index and b) cytogenetic analysis for chromosomal instability, immunocytochemistry of anti-pericentrin antibody, DNA ploidy analysis and ISSR-PCR for evaluation of microsatellite instability. Studies were conducted at different intervals $(\mathrm{N}=3)$ ranging from 6 to $96 \mathrm{~h}$ for the former, whereas cells were subjected to analysis at every passage from first to fifth for the latter. Experiments were performed with a fixed $0.005 \mu \mathrm{M}(1 \mu \mathrm{g} / \mu \mathrm{L})$ concentration of $\mathrm{N}$-succinimidyl $\mathrm{N}$-methylcarbamate in cultured IMR-90 human lung fibroblasts for both sections.

\section{Measurement of inflammatory response}

Supernatants collected from cultures were examined for inflammatory response by determining the levels of cytokines IL-8, IL-1 $\beta$, IL-6, IL-10, TNF, and IL-12 p70 and the assays were performed according to manufacturer instructions. Data acquisition and analysis were carried out on a flow cytometric platform using the $\mathrm{BD}^{\mathrm{TM}} \mathrm{CBA}$ software.

\section{Evaluation of DNA damage}

Study of DNA damage kinetics was performed through qualitative and quantitative analysis of ATR/ATM/H2AX/p53. Cells were grown overnight on slides in EMEM and subjected to $\mathrm{N}$-succinimidyl $\mathrm{N}$-methylcarbamate treatment for $6 \mathrm{~h}$. The cells were then fixed with $10 \%$ formaldehyde for $1 \mathrm{~h}$ and permeabilized with $0.1 \%$ Triton-X-100 for 30 min, blocked with $3 \%$ BSA for $3 \mathrm{~h}$, and then incubated with anti-ATM/anti-ATR/anti-H2AX/ anti-p53 antibodies (dilution 1:1000) for $3 \mathrm{~h}$ and FITC-conjugated secondary antibodies (dilution 1:200) for $1 \mathrm{~h}$. For qualitative analysis, nuclear and cytoskeletal counterstaining with 4', 6'-diamidino-2-phenylindole dihydrochloride and phalloidin (phalloidin red for ATM and phalloidin green for p53) was performed respectively and immediately mounted with antifade solution, cover slipped and stored in the dark at $4^{\circ} \mathrm{C}$. The images were then 
acquired by a spectral bio-imaging system and analyzed with the Spectral Imaging 4.0 software (Applied Spectral Imaging, Israel). For quantitative measurement, the immunostained cells were then assessed by flow cytometer (FACS Calibur, BD-IS, USA), and cell associated fluorescence in FL1 channel was analyzed for 10,000 total events.

\section{Assessment of apoptotic index}

Measurement of apoptotic index of cultured cells was performed using the AnnexinV-FITC/PI assay kit according to manufacturer recommendations. From each cell, forward light scatter (FSC), orthogonal light scatter (SSC), and annexin-V-FITC and PI fluorescence were measured using the Cell-Quest software (BD-IS, USA). The gate was applied in the FSC/ SSC dot plot to restrict the analysis to cultured cells only. For the gated cells, the percentages of annexin-V-FITC-positive or -negative or PI-positive or -negative cells were evaluated. In each case total 10,000 events were recorded in HI mode with 10/10 log quadrant gate.

\section{Evaluation of genomic instability}

\section{Chromosomal instability}

For evaluation of chromosomal instability, exponentially growing (50-80\% confluence) IMR-90 cell cultures were exposed to $0.04 \mu \mathrm{g} / \mathrm{mL}$ colchicine (Sigma) for $3-4 \mathrm{~h}$ at $37^{\circ} \mathrm{C}$. Metaphase spreads were prepared and stained by conventional methods as described previously (Schaefer et al., 1993). A minimum of 50 metaphases for control and treated cells were selected and photographed and analyzed using the Spectral Imaging 4.0 software, to determine chromosome frequency distribution and morphology. For immunocytochemistry of anti-pericentrin antibody analysis, protocols were performed as mentioned above.

\section{Analysis of DNA ploidy}

Analysis of DNA ploidy was performed by staining the cultured cells with PI using the Cycle TEST PLUS DNA Reagent kit according to the manufacturer protocol. PI fluorescence was measured with BD ${ }^{\mathrm{TM}}$ FACS Calibur using the Cell-Quest software. A total of 30,000 events were acquired in LO mode and were subjected for analysis by the Cell-Quest software.

\section{Microsatellite instability}

Assessment of microsatellite instability by ISSR-PCR was done by extracting genomic DNA using the supplier's protocol and thus $50 \mathrm{ng}$ of the extracted DNA was amplified in a $10-\mu \mathrm{L}$ reaction mixture containing $1 \mathrm{X}$ PCR buffer, $200 \mu \mathrm{M}$ deoxynucleoside triphosphates, $1.5 \mathrm{mM} \mathrm{MgCl}, 2.5 \mu \mathrm{M}$ of one of the base-anchored dinucleotide repeat $(\mathrm{CA})_{8}$ primers, 0.5 units Taq DNA polymerase. The cycling conditions were 3 min initial denaturation at $94^{\circ} \mathrm{C}$, 30 cycles of $30 \mathrm{~s}$ at $94^{\circ} \mathrm{C}, 45 \mathrm{~s}$ at $50^{\circ} \mathrm{C}$, and $2 \mathrm{~min}$ at $72^{\circ} \mathrm{C}$, followed by a final extension for 7 min at $72^{\circ} \mathrm{C}$. Genomic alterations were detected as gains and losses of specific bands following analysis of the PCR product on $8 \%$ non-denaturing polyacrylamide gels containing $5 \%$ glycerol using a gel documentation system (Vilber Lourmat, France). 


\section{RESULTS}

\section{Estimation of inflammation}

Flow cytometric analysis revealed a time-dependent response in the levels of the inflammatory cytokines IL-8, IL-1 $\beta$, IL-6, IL-10, TNF, and IL-12 p70 in cell culture supernatant of the IMR-90 cells treated with $0.005 \mu \mathrm{M}(1 \mu \mathrm{g} / \mu \mathrm{L})$ concentration of N-succinimidyl N-methylcarbamate. Representative multiplex CBA assay data for increase in levels of cytokines secreted in culture supernatant following treatment as compared to control are shown in Figure 1.

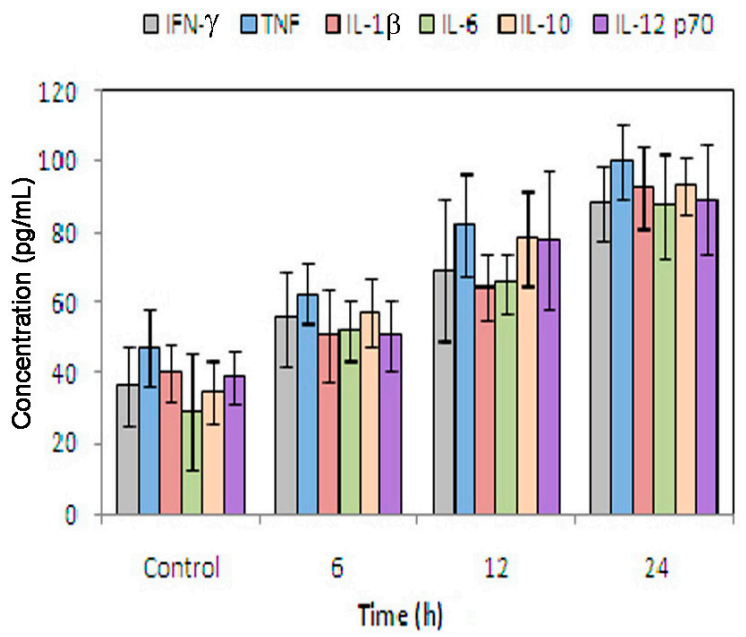

Figure 1. Graph demonstrating the elevated levels of inflammatory cytokines (IL-8, TNF, IL-1 $\beta$, IL-6, IL-10, IL-12 p70) in the IMR-90 cells treated with $0.005 \mu \mathrm{M}(1 \mu \mathrm{g} / \mu \mathrm{L})$ concentration of $\mathrm{N}$-succinimidyl N-methylcarbamate after 6,12 , and $24 \mathrm{~h}$ in comparison to controls. The levels of inflammatory cytokines were incremental in a time-dependent manner as compared to controls. IFN- $\gamma=$ interferon gamma; $\mathrm{TNF}=$ tumor necrosis factor; $\mathrm{IL}=$ interleukin.

\section{Evaluation of DNA damage}

A prerequisite for maintaining genome stability in all cell types is the efficient signaling of DNA double-strand breaks. DNA damage analysis of IMR-90 cells treated with constant $0.005 \mu \mathrm{M}(1 \mu \mathrm{g} / \mu \mathrm{L})$ concentration of $\mathrm{N}$-succinimidyl N-methylcarbamate showed various morphological alterations. As compared with controls the post-treatment immunofluorescence analysis of cells showed elevated phosphorylation profile of ATM/ATR at Ser431/Ser1981 in punctuated nuclear pattern. Subsequent increase in $\gamma \mathrm{H} 2 \mathrm{AX}$ and $\mathrm{p} 53$ phosphorylation at Ser139 and Ser15, respectively, was also observed in the cells following treatment in comparison with their respective controls (Figure 2) suggestive of nuclear retention of these factors by the appearance of foci. In addition, a time-dependent increase in the activity of ATM/ATR/ $\gamma \mathrm{H} 2 \mathrm{AX} / \mathrm{p} 53$ was observed. The maximum activity of ATM was $57.31 \%$ at $6 \mathrm{~h}$ while the activity of ATR $/ \gamma \mathrm{H} 2 \mathrm{AX} / \mathrm{p} 53$ reached a maximum of $58.41,67.22$, and $74.91 \%$, respectively, at 12 $\mathrm{h}$ (Figure 3 ) in the cells treated with $\mathrm{N}$-succinimidyl N-methylcarbamate. 

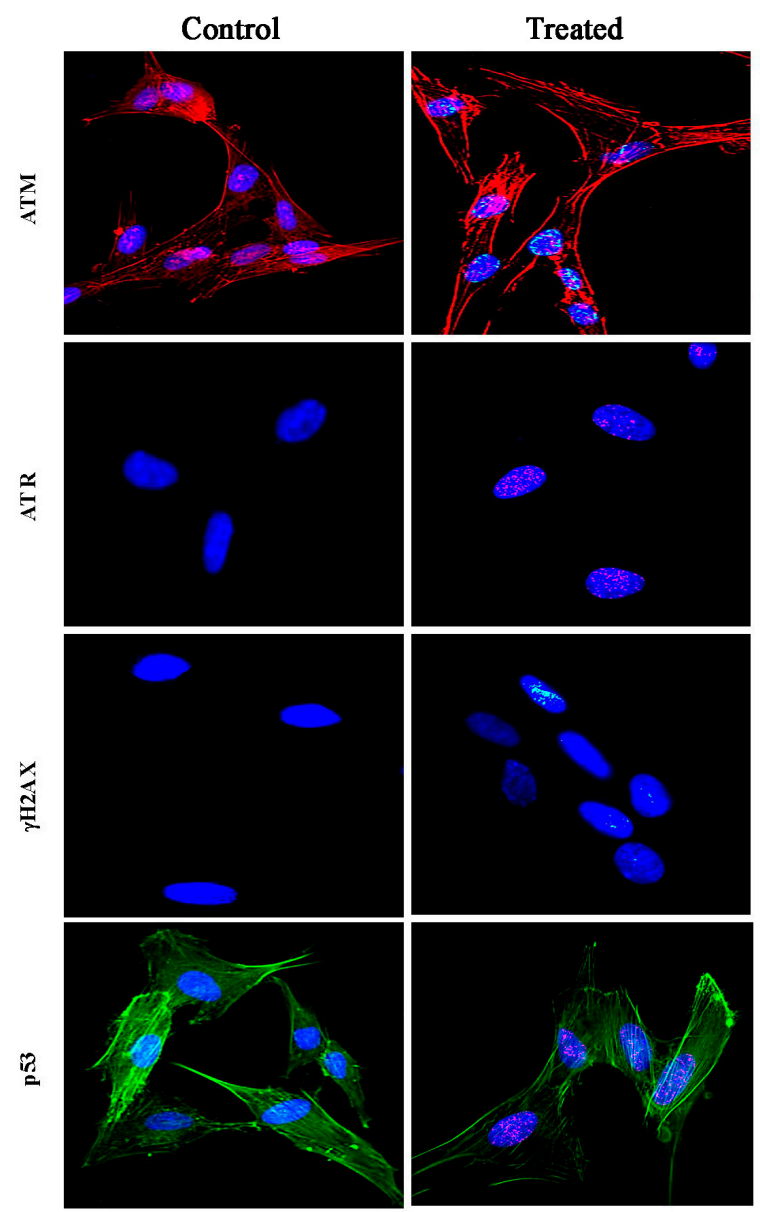

Figure 2. Microphotographs (200X) of immunofluorescence analysis of ATM/ATR $/ \gamma \mathrm{H} 2 \mathrm{AX} / \mathrm{p} 53$ phosphorylation with significant punctuated nuclear patterns in IMR-90 (human lung fibroblast) cells following treatment with $0.005 \mu \mathrm{M}(1 \mu \mathrm{g} / \mu \mathrm{L})$ concentration of $\mathrm{N}$-succinimidyl $\mathrm{N}$-methylcarbamate at $6 \mathrm{~h}$ (right panels) in comparison to controls (left panels). ATM = ataxia telangiectasia mutated; $\mathrm{ATR}=$ ataxia telangiectasia and $\mathrm{Rad} 3$ related; $\gamma \mathrm{H} 2 \mathrm{AX}$ and $\mathrm{p} 53=$ proteins involved in DNA damage response.

\section{Assessment of apoptotic index}

Following the induction of DNA damage, a prominent route of cell inactivation is apoptosis. A substantial increase in apoptosis in the cells following treatment was observed by annexin- $\mathrm{V} /$ PI staining, which detects apoptotic cells at significantly earlier stages. The number of cells undergoing apoptosis was incremental with increase in the duration of N-succinimidyl N-methylcarbamate exposure to the processed IMR-90 cells. The peak value of $50.18 \pm 12.75$ were observed at 24 $\mathrm{h}$ post-treatment in contrast to the control value $3.41 \pm 0.03$ (Figures 3 and 4). 


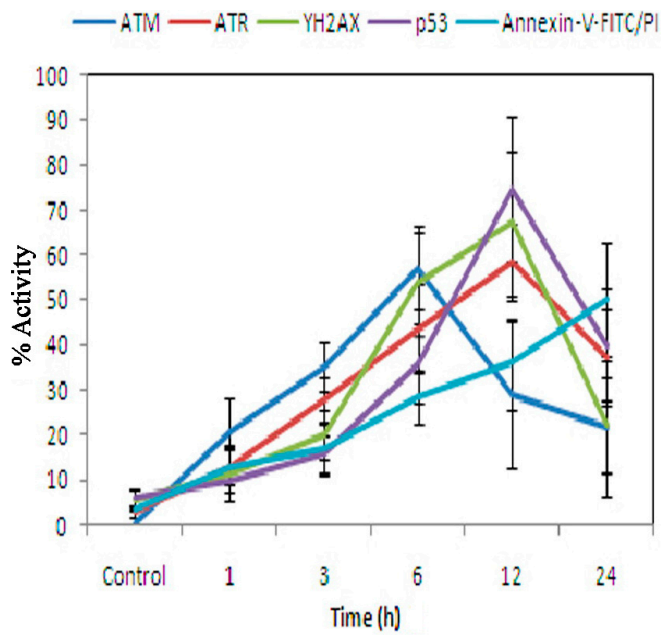

Figure 3. Graphical representation of the $\mathrm{ATM} / \mathrm{ATR} / \gamma \mathrm{H} 2 \mathrm{AX} / \mathrm{p} 53$ activity and apoptotic index in cells treated with $0.005 \mu \mathrm{M}(1 \mu \mathrm{g} / \mu \mathrm{L})$ concentration of $\mathrm{N}$-succinimidyl N-methylcarbamate for 6,12 , and $24 \mathrm{~h}$ in comparison with their respective controls. FITC = fluorescein isothiocyanate; PI = propidium iodide. For other abbreviations, see legend to Figure 2.
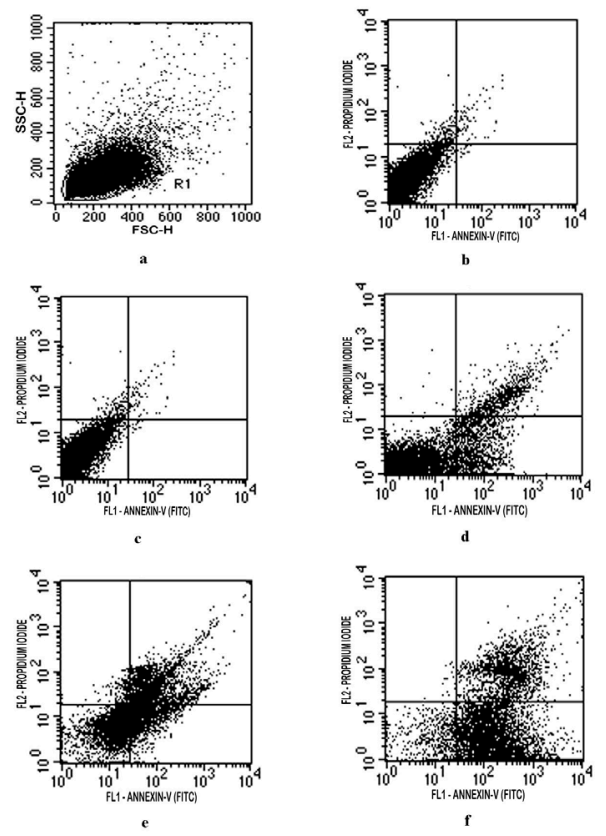

Figure 4. Flow cytometric analysis for apoptosis in cultured IMR-90 (human lung fibroblast) cells following treatment with N-succinimidyl N-methylcarbamate: (a) forward light scatter/orthogonal light scatter (FSC/SSC) dot plot showing the population of IMR-90 cells; (b) control cells; (c-f) cells treated with a fixed dose $(5 \mu \mathrm{g})$ of $\mathrm{N}$-succinimidyl $\mathrm{N}$-methylcarbamate at $6,12,24,48 \mathrm{~h}$ showing time-dependent increase in apoptotic index. Apoptotic index is the sum of the percentage of cells that are positive for annexin-V-fluorescein isothiocyanate (FITC) alone and cells positive for both annexin-V-FITC and propidium iodide within a population of cells. 


\section{Evaluation of genomic instability}

\section{Chromosomal instability}

The ability of N-succinimidyl N-methylcarbamate to induce chromosomal instability was evident from the results obtained with cytogenetic analysis. Structural aberrations at the chromosomal level including dicentrics, chromatid breaks, fragments of chromatids and, notably, numerical polyploidization of chromosomes at the 5th passage were observed on cytogenetic examination of the cells following treatment (Figures 5 and 6 ).
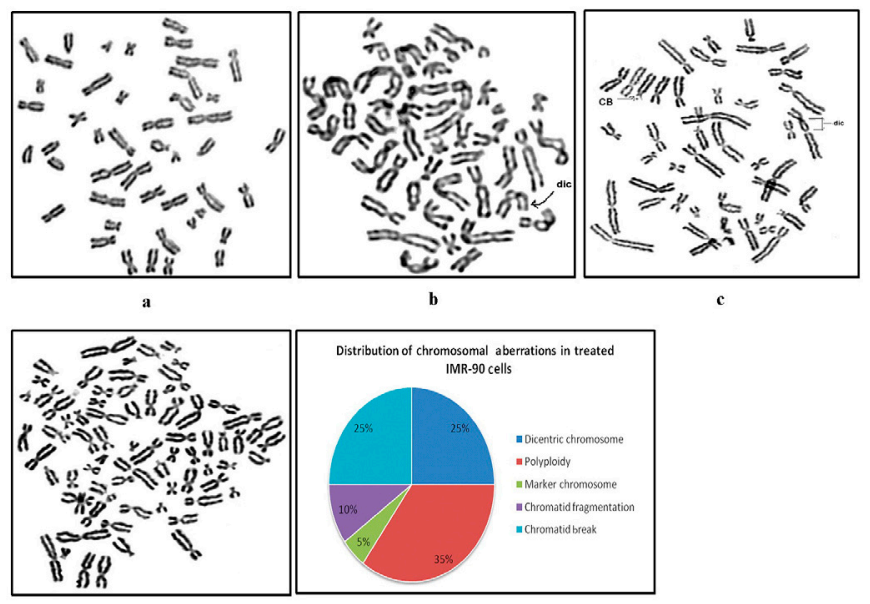

of

Figure 5. Representative metaphase spreads of IMR-90: (a) control cells showing normal karyotype; (b-d) $\mathrm{N}$-succinimidyl N-methylcarbamate-treated cells showing dicentric chromosomes, chromatid breaks, and near polyploidy chromosomes during 1st-5th passages. (e) Pie diagram illustrating distribution of chromosomal abnormalities observed in N-succinimidyl N-methylcarbamate-treated cells.

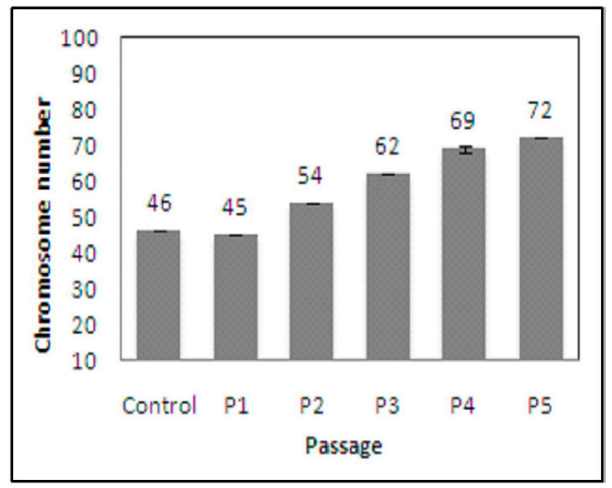

Figure 6. Histogram demonstrating variation in chromosome numbers of treated IMR-90 cells after 1st, 2nd, 3rd, 4th, and 5th passages (P1-P5) in comparison to control cells.

In addition, an abnormal centrosome functioning was indicated by the immunocytochemistry analysis of the treated cells, which displayed a 4-fold increase in the levels of pericentriolar protein pericentrin (Figure 7). 

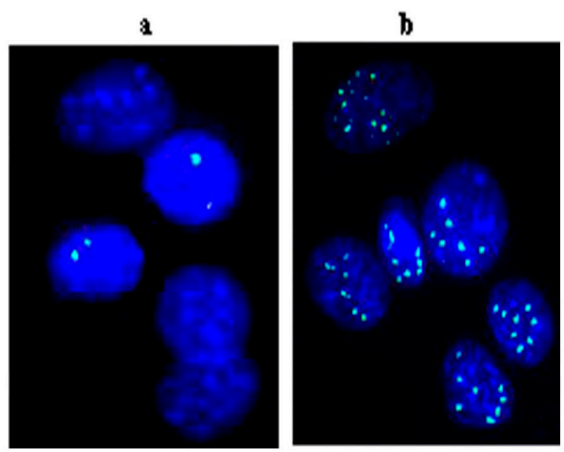

Figure 7. Immunofluorescence images (200X) showing over expression of pericentrin by 4-fold in N-succinimidyl $\mathrm{N}$-methylcarbamate-treated cells in comparison to control. (a) Control cells; (b) N-succinimidyl N-methylcarbamatetreated IMR-90 cells after the 5 th passage.

\section{Analysis of DNA ploidy}

Flow cytometry demonstrated that there is an apparent aneuploidy of chromosomal DNA (Figure 8). Assessment of DNA ploidy of cells following treatment with $0.005 \mu \mathrm{M}(1$ $\mu \mathrm{g} / \mu \mathrm{L}$ ) concentration of N-succinimidyl N-methylcarbamate from passage 1 through passage 5 showed onset of aneuploidy in comparison to the control.
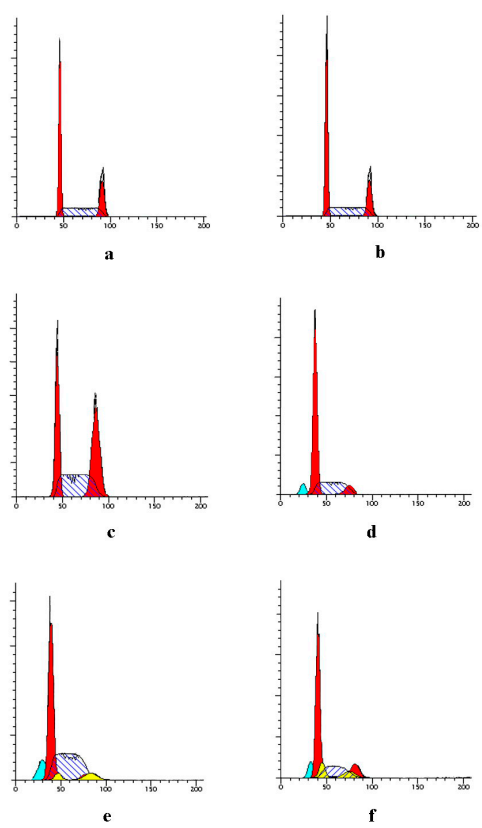

Figure 8. Inclination of aneuploidy in treated cells: (a) Control cells; (b) significant arrest of cells as evident in G1 phase after $24 \mathrm{~h}$ of treatment; (c) onset of G2/M arrest after $48 \mathrm{~h}$ of treatment; (d) a distinct sub-G1 peak showing cells undergoing apoptosis at $96 \mathrm{~h}$ of treatment; (e,f) $0.005 \mu \mathrm{M}(1 \mu \mathrm{g} / \mu \mathrm{L}) \mathrm{N}$-succinimidyl N-methylcarbamatetreated IMR-90 cells after 1st and 5th passages showing both aneuploidy and apoptosis. 


\section{Microsatellite instability}

Microsatellite instability is a condition manifested by DNA damage due to defects in the normal DNA repair process. Sections of DNA called microsatellites, which consist of a sequence of repeating units of 1-6 bp in length, become unstable and can shorten or lengthen. Notably, significant alterations at microsatellite levels in the genome of the IMR cells treated with the chemical agent were observed. The results displayed by ISSR-PCR showed significant variations, observed as absence and increased/decreased intensity of bands, which were due to the variable amplification of ISSR (CA) $)_{8}$ (Figure 9).

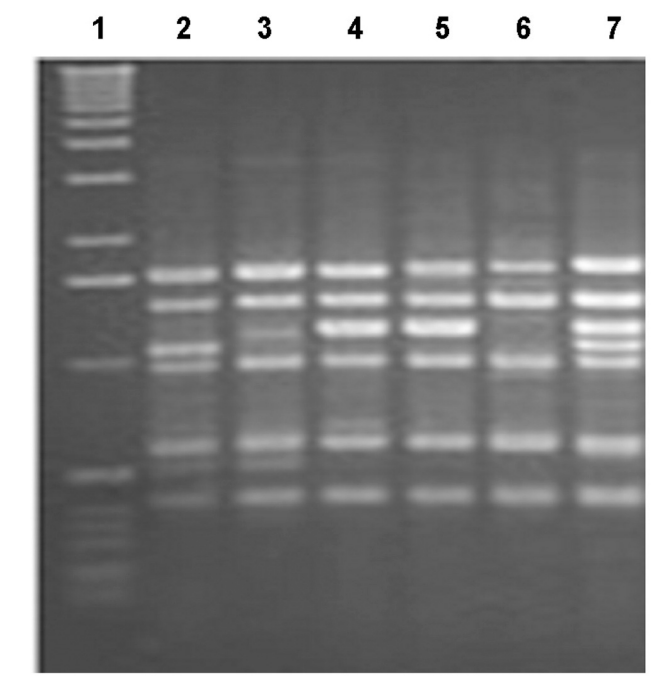

Figure 9. Microphotograph displaying the fluctuating inter-simple sequence repeat banding pattern of microsatellite repeats $(\mathrm{CA})_{8}$ of control and treated cells. Lane 1: low base pair marker (100 bp); lane 2: control of passage 1; lane 3 : treated cells of passage 1; lane 4: treated cells of passage 2; lane 5: treated cells of passage 3; lane 6: treated cells of passage 4; lane 7: treated cells of passage 5 .

\section{DISCUSSION}

The present investigation demonstrated the spontaneous ability of isocyanates to induce inflammatory conditions as a significant increase in the levels of inflammatory cytokines in treated cells. Moreover, an increased extent of DNA damage and apoptosis following exposure was also observed. Pericentrin immunolabeling, ploidy analysis, and also the analysis through ISSR-PCR showed a greater instability at both the chromosomal and microsatellite level, thus demonstrating that these are endpoints of genomic instability.

The genetic link between chronic lung inflammation and lung cancer has recently been reviewed (Brody and Spira, 2006; Schwartz et al., 2007). Additionally, it has been speculated that chronic inflammation leads to cancer progression through the induction of inappropriate gene expression, enhanced proliferation of initiated cells, inadequate apoptosis, metastasis, etc. Inflammation-induced damage to important cellular components (e.g., DNA, proteins and lipids) can directly or indirectly contribute to malignant cell transformation (Kundu and Surh, 
2008). Previous studies on isocyanates and their derivatives including MIC have reported that isocyanates are highly reactive and capable of inducing inflammation (Vijayan and Sankaran, 1996). The results displayed here are in congruence with the idea that isocyanate exposure can lead to inflammatory conditions (Piirila et al., 2008; Mishra et al., 2008). Elevated levels of inflammatory cytokines in the IMR-90 human lung fibroblasts treated with N-succinimidyl Nmethylcarbamate were found to be time-dependent (Figure 1). Moreover, chronic inflammation is also associated with genomic instability (Hofseth et al., 2003), and this unstable genome is believed to act as a driving force in inducing carcinogenesis (Rajagopalan et al., 2003).

Upon genotoxic, stress serine/threonine protein kinases ATR and ATM act as DNA damage sensors and any kind of mutations in these kinases results in a variety of diseases (O'Driscoll et al., 2003). Incidentally, ATM gene mutations are implicated in many human cancers including lung cancer (Xing et al., 2008). Moreover, p53 tumor suppressor is considered to be a mutational target of many environmental carcinogens (Xiao and Singh, 2007), and previous studies have reported that p53 mutations are common in lung cancer and range from 40 to $70 \%$ (Zhang et al., 2006; Bumroongkit et al., 2008). Previous data have shown that MIC exposure can lead to a series of biotransformation reactions in mammals (Slatter et al., 1991), thereby exerting mutagenic and genotoxic alterations (Anderson et al., 1988). The results of the qualitative study of the IMR-90 cells treated with N-succinimidyl $\mathrm{N}$-methylcarbamate in the present investigation showed an elevated expression of phosphoATR, phospho-ATM, phospho-p53, and accumulated phospho-H2AX foci indicative of increased nuclear relocalization through aggregates and enhanced binding to the damaged sites (Figure 2). Increased activity of p53 in the treated cells indicated its activation through phosphorylation by serine/threonine protein kinases. In addition, our results demonstrate that phosphorylation of p53 (ser15) and histone H2AX (ser139) in response to isocyanate exposure depends on both ATM and ATR. Flow cytometric observations further clarified the above results as a time-dependent increase in the activity of these proteins (Figure 3).

When activated by DNA lesions, these complex and interconnected pathways trigger a variety of cellular responses, including cell cycle arrest via the activation of checkpoints, and apoptosis. Some of these responses such as transient arrest of the cell cycle may facilitate the repair of damaged chromosomes and are thought to be protective and to enhance cell survival while other responses including apoptosis eliminate the clonogenic potential of damaged cells, thus preventing the propagation of acquired mutations. It has been shown in previous studies that defective cellular responses can lead to genetic alteration, chromosomal instability, and ultimately malignant transformation (Mills et al., 2003). Escalation in the apoptotic index of treated cells in a time-dependent manner further demonstrates the increased inclination of treated cells to undergo apoptosis. The maximum apoptotic index was observed after $24 \mathrm{~h}$ of exposure (Figures 3 and 4 ) further indicating that the response to the extent of DNA damage occurred due to the toxic exposure.

Studies conducted on the lung cancer have shown frequent genomic imbalances (Markovic et al., 2008), and it is suggested that chromosomal instability plays an important role in its progression (Ninomiya et al., 2006). Structural chromosomal rearrangements and losses/gains from non-disjunctions and multipolar mitoses are thought to result in aneuploidy. Aneuploidy is a steady source of chromosomal variations where in it unbalances thousands of genes and corrupts teams of proteins that segregate, synthesize and repair chromosomes (Duesberg et al., 2005). The results observed on cytogenetic analysis of IMR-90 
cells following exposure to N-succinimidyl N-methylcarbamate collectively confirmed that there is a synergistic instigation of instability in the genome as indicated by various structural chromosomal abnormalities (Figure 5a-e) and numerical discrepancy in chromosome number all through passage 1 to passage 5 (Figure 6). The patterns observed might have resulted from endoreduplication/s that occurred after some chromosomal rearrangements. Correspondingly, DNA ploidy analysis displayed an apparent aneuploidy of the chromosomal DNA at 1 st and 5th passage levels (Figure 8). Hence, these unstable-type chromosome aberrations provide evidence that they are the hallmarks of chromosomal instability.

Moreover, it is well known that the normal functioning of centrosomes, including organization of the cytoskeleton, mitotic spindle and cell cycle progression, is supported by pericentrin, a protein present in it (Chen et al., 2004; Doxsey et al., 2005). Prior studies have reported that perturbed pericentrin function leads to defective mitotic spindle assembly (Pihan et al., 2003). Concurrently, there was a 4-fold increase in pericentrin levels in the cells following treatment suggestive of a defective centrosome functioning, thereby generating supernumerary centrioles leading to multipolar mitoses due to improper segregation of chromosomes during cell division (Figure 7). Furthermore, the association of lung carcinoma with the instability at microsatellite level has been recently illustrated (Tseng et al., 2008). In this regard, the evaluation of instability at the microsatellite level strengthened our present findings with the display of variable distribution pattern of ISSR (CA) $)_{8}$ as observed in the form of gains, losses, or intensity changes in the number of bands in treated cells in comparison to controls (Figure 9).

In conclusion, our results indicate that isocyanates induce inflammation, DNA damage, cell cycle arrest, apoptosis, and more broadly genomic instability in the IMR-90 human lung fibroblasts. Our findings enhance our current understanding of the relevance of alterations at genomic level occurring due to harmful consequences of genetic insults. Further studies are clearly needed to confirm a possible mechanistic role of isocyanate-induced genomic alterations in relation to the development of carcinogenicity. We hope that these data along with other studies reported in the literature will help to design better approaches in risk assessment of occupational and accidental exposure to isocyanates.

\section{ACKNOWLEDGMENTS}

The authors are thankful to Bhopal Memorial Hospital Trust, India, for providing financial support and to Mr. Naveen Kumar Khare for providing the necessary technical assistance.

\section{REFERENCES}

Abraham RT (2004). PI 3-kinase related kinases: 'big' players in stress-induced signaling pathways. DNA Repair 3: 883-887. Anderson D, Goyle S, Phillips BJ, Tee A, et al. (1988). Effects of methyl isocyanate on rat muscle cells in culture. Br. $J$. Ind. Med. 45: 269-274.

Baur X (2003). Isocyanates: occupational exposures and disorders. Pneumologie 57: 526-531.

Beyerbach A, Farmer PB and Sabbioni G (2006). Biomarkers for isocyanate exposure: Synthesis of isocyanate DNA adducts. Chem. Res. Toxicol. 19: 1611-1618.

Brody JS and Spira A (2006). State of the art. Chronic obstructive pulmonary disease, inflammation, and lung cancer. Proc. Am. Thorac. Soc. 3: 535-537.

Bumroongkit K, Rannala B, Traisathit P, Srikummool M, et al. (2008). TP53 gene mutations of lung cancer patients in upper northern Thailand and environmental risk factors. Cancer Genet. Cytogenet. 185: 20-27.

Chen D, Purohit A, Halilovic E, Doxsey SJ, et al. (2004). Centrosomal anchoring of protein kinase C betaII by pericentrin 
controls microtubule organization, spindle function, and cytokinesis. J. Biol. Chem. 279: 4829-4839.

Coussens LM and Werb Z (2002). Inflammation and cancer. Nature 420: 860-867.

Doxsey S, Zimmerman W and Mikule K (2005). Centrosome control of the cell cycle. Trends Cell Biol. 15: 303-311.

Duesberg P, Li R, Fabarius A and Hehlmann R (2005). The chromosomal basis of cancer. Cell Oncol. 27: 293-318.

Gorgoulis VG, Vassiliou LV, Karakaidos P, Zacharatos P, et al. (2005). Activation of the DNA damage checkpoint and genomic instability in human precancerous lesions. Nature 434: 907-913.

Hofseth LJ, Khan MA, Ambrose M, Nikolayeva O, et al. (2003). The adaptive imbalance in base excision-repair enzymes generates microsatellite instability in chronic inflammation. J. Clin. Invest. 112: 1887-1894.

Ishikawa K, Ishii H and Saito T (2006). DNA damage-dependent cell cycle checkpoints and genomic stability. DNA Cell Biol. 25: 406-411.

Kang J, Ferguson D, Song H, Bassing C, et al. (2005). Functional interaction of H2AX, NBS1, and p53 in ATM-dependent DNA damage responses and tumor suppression. Mol. Cell Biol. 25: 661-670.

Kundu JK and Surh YJ (2008). Inflammation: gearing the journey to cancer. Mutat. Res. 659: 15-30.

Lee CT, Ylostalo J, Friedman M and Hoyle GW (2005). Gene expression profiling in mouse lung following polymeric hexamethylene diisocyanate exposure. Toxicol. Appl. Pharmacol. 205: 53-64.

Liloglou T, Maloney P, Xinarianos G, Hulbert M, et al. (2001). Cancer-specific genomic instability in bronchial lavage: a molecular tool for lung cancer detection. Cancer Res. 61: 1624-1628.

Mantovani A, Allavena P, Sica A and Balkwill F (2008). Cancer-related inflammation. Nature 454: 436-444.

Markovic J, Stojsic J, Zunic S, Ruzdijic S, et al. (2008). Genomic instability in patients with non-small cell lung cancer assessed by the arbitrarily primed polymerase chain reaction. Cancer Invest. 26: 262-268.

Martinez J, Oiry J, Imbach JL and Winternitz F (1982). Activated N-nitrosocarbamates for region selective synthesis of N-nitrosoureas. J. Med. Chem. 25: 178-182.

Mikoczy Z, Welinder H, Tinnerberg H and Hagmar L (2004). Cancer incidence and mortality of isocyanate exposed workers from the Swedish polyurethane foam industry: updated findings 1959-98. Occup. Environ. Med. 61: 432-437.

Mills KD, Ferguson DO and Alt FW (2003). The role of DNA breaks in genomic instability and tumorigenesis. Immunol. Rev. 194: 77-95.

Mishra PK, Panwar H, Bhargava A, Gorantla VR, et al. (2008). Isocyanates induces DNA damage, apoptosis, oxidative stress, and inflammation in cultured human lymphocytes. J. Biochem. Mol. Toxicol. 22: 429-440.

Ninomiya H, Nomura K, Satoh Y, Okumura S, et al. (2006). Genetic instability in lung cancer: concurrent analysis of chromosomal, mini- and microsatellite instability and loss of heterozygosity. Br. J. Cancer 94: 1485-1491.

O’Driscoll M, Ruiz-Perez VL, Woods CG, Jeggo PA, et al. (2003). A splicing mutation affecting expression of ataxiatelangiectasia and Rad3-related protein (ATR) results in Seckel syndrome. Nat. Genet. 33: 497-501.

Pihan GA, Wallace J, Zhou Y and Doxsey SJ (2003). Centrosome abnormalities and chromosome instability occur together in pre-invasive carcinomas. Cancer Res. 63: 1398-1404.

Piirila PL, Meuronen A, Majuri ML, Luukkonen R, et al. (2008). Inflammation and functional outcome in diisocyanateinduced asthma after cessation of exposure. Allergy 63: 583-591.

Rajagopalan H, Nowak MA, Vogelstein B and Lengauer C (2003). The significance of unstable chromosomes in colorectal cancer. Nat. Rev. Cancer 3: 695-701.

Redlich CA and Herrick CA (2008). Lung/skin connections in occupational lung disease. Curr. Opin. Allergy Clin. Immunol. 8: 115-119.

Schaefer DI, Livanos EM, White AE and Tlsty TD (1993). Multiple mechanisms of N-(phosphonoacetyl)-L-aspartate drug resistance in SV40-infected precrisis human fibroblasts. Cancer Res. 53: 4946-4951.

Schwartz AG, Prysak GM, Bock CH and Cote ML (2007). The molecular epidemiology of lung cancer. Carcinogenesis 28: 507-518.

Shiloh Y and Lehmann AR (2004). Maintaining integrity. Nat. Cell Biol. 6: 923-928.

Slatter JG, Rashed MS, Pearson PG, Han DH, et al. (1991). Biotransformation of methyl isocyanate in the rat. Evidence for glutathione conjugation as a major pathway of metabolism and implications for isocyanate-mediated toxicities. Chem. Res. Toxicol. 4: 157-161.

Tibbetts RS, Brumbaugh KM, Williams JM, Sarkaria JN, et al. (1999). A role for ATR in the DNA damage-induced phosphorylation of p53. Genes Dev. 13: 152-157.

Tseng RC, Hsieh FJ, Hsu HS and Wang YC (2008). Minimal deletion regions in lung squamous cell carcinoma: association with abnormality of the DNA double-strand break repair genes and their applications on gene identification and prognostic biomarkers. Lung Cancer 59: 332-339.

Vijayan VK and Sankaran K (1996). Relationship between lung inflammation, changes in lung function and severity of exposure in victims of the Bhopal tragedy. Eur. Respir. J. 9: 1977-1982.

Genetics and Molecular Research 8 (1): 129-143 (2009)

(CFUNPEC-RP www.funpecrp.com.br 
Xiao H and Singh SV (2007). p53 regulates cellular responses to environmental carcinogen benzo[a]pyrene-7,8-diol-9,10epoxide in human lung cancer cells. Cell Cycle 6: 1753-1761.

Xing J, Wu X, Vaporciyan AA, Spitz MR, et al. (2008). Prognostic significance of ataxia-telangiectasia mutated, DNAdependent protein kinase catalytic subunit, and Ku heterodimeric regulatory complex $86-\mathrm{kD}$ subunit expression in patients with nonsmall cell lung cancer. Cancer 112: 2756-2764.

Zhang X, Miao X, Guo Y, Tan W, et al. (2006). Genetic polymorphisms in cell cycle regulatory genes MDM2 and TP53 are associated with susceptibility to lung cancer. Hum. Mutat. 27: 110-117.

Zhou BB and Elledge SJ (2000). The DNA damage response: putting checkpoints in perspective. Nature 408: 433-439. 